\title{
Emergence of high drug resistant bacterial isolates from patients with health care associated infections at Jimma University medical center: a cross sectional study
}

Mulatu Gashaw ${ }^{1,11^{*}}$, Melkamu Berhane ${ }^{2}$, Sisay Bekele ${ }^{3}$, Gebre Kibru$^{1}$, Lule Teshager ${ }^{1}$, Yonas Yilma ${ }^{4}$, Yesuf Ahmed ${ }^{5}$, Netsanet Fentahun ${ }^{6}$, Henok Assefa ${ }^{7}$, Andreas Wieser ${ }^{8}$, Esayas Kebede Gudina ${ }^{9}$ and Solomon Ali $^{1,10}$

\begin{abstract}
Background: The rates of resistant microorganisms which complicate the management of healthcare associated infections (HAls) are increasing worldwide and getting more serious in developing countries. The objective of this study was to describe microbiological features and resistance profiles of bacterial pathogens of HAls in Jimma University Medical Center (JUMC) in Ethiopia.

Methods: Institution based cross sectional study was carried out on hospitalized patients from May to September, 2016 in JUMC. Different clinical specimens were collected from patients who were suspected to hospital acquired infections. The specimens were processed to identify bacterial etiologies following standard microbiological methods. Antibacterial susceptibility was determined in vitro by Kirby-Bauer disk diffusion method following Clinical and Laboratory Standards Institute guidelines.

Results: Overall, 126 bacterial etiologies were isolated from 118 patients who had HAls. Of these, 100 (79.4\%) were gram negative and the remaining were gram positive. The most common isolates were Escherichia coli $31(24.6 \%)$, Klebsiella species 30(23.8\%) and Staphylococcus aureus 26 (20.6\%). Of 126 bacterial isolates, 38 (30. 2\%), 52 (41.3\%), and 24 (19\%) were multidrug-resistant (MDR, resistant to at least one agent in three or more antimicrobial categories), extensively drug resistant (XDR, resistant to at least one agent in all but two or fewer antimicrobial categories (i.e. bacterial isolates remain susceptible to only one or two categories), pan-drug resistant (PDR, resistant to all antibiotic classes) respectively. More than half of isolated gram-negative rods (51\%) were positive for extended spectrum beta-lactamase (ESBL) and/or AmpC; and 25\% of gram negative isolates were also resistant to carbapenem antibiotics.
\end{abstract}

Conclusions: The pattern of drug resistant bacteria in patients with healthcare associated infection at JUMC is alarming. This calls for coordinated efforts from all stakeholders to prevent HAls and drug resistance in the study setting.

Keywords: Antimicrobial agents, Drug resistant isolates, Multidrug resistance, Extensively resistance, Pandrug resistance, Carbapenem resistance, Extended spectrum beta-lactamase

\footnotetext{
*Correspondence: mulatugashaw@gmail.com; mulatu.gashaw@ju.edu.et

${ }^{1}$ School of Medical Laboratory Science, Jimma University, Jimma, Ethiopia

${ }^{11}$ Institute of Health, Jimma University, P.O. Box 1368, Jimma, Ethiopia

Full list of author information is available at the end of the article
}

(c) The Author(s). 2018 Open Access This article is distributed under the terms of the Creative Commons Attribution 4.0 International License (http://creativecommons.org/licenses/by/4.0/), which permits unrestricted use, distribution, and reproduction in any medium, provided you give appropriate credit to the original author(s) and the source, provide a link to the Creative Commons license, and indicate if changes were made. The Creative Commons Public Domain Dedication waiver (http://creativecommons.org/publicdomain/zero/1.0/) applies to the data made available in this article, unless otherwise stated. 


\section{Introduction}

The emergence and rapid spread of multidrug resistant pathogenic bacteria is becoming a global health challenge [1]. Recent studies showed an increasing rate of bacterial resistance against available antibiotics. The problem is more pronounced in developing countries attributed to limited antibiotic option, irrational drug use, poor drug quality, poor sanitation, malnutrition, poor and inadequate health care systems, and lack of control for antibiotic use and stewardship program [2, 3].

In the past few decades, antimicrobial drugs have saved many lives and reduced the grief of many million people globally [3]. However, the extraordinary benefits of antimicrobials in reducing morbidity and mortality have been challenged by the emergence of drug resistant bacteria. The recent emergence and spread of these resistant bacteria have become a serious public health concern [4]. Especially, the spread of such bacteria in resource limited countries would have devastating consequences considering the health infrastructure, antibiotic options available and over all resource constraints observed in such countries [5].

In recent years, high dissemination of ESBL producing, carbapenem, and methicillin resistant bacteria are observed worldwide $[6,7]$. It is described that the problem of ESBL-producing organisms is more intense in developing countries [8]. However, the magnitude of the problem is still probably underestimated due to inadequate or ineffective detection in some clinical settings $[3,7,9]$. ESBLs are a group of plasmid-mediated, diverse, complex and rapidly evolving enzymes which are capable of hydrolyzing penicillin's, broad-spectrum cephalosporin's and monobactam's [10]. Accordingly, ESBL enzyme producing bacteria have a capacity to resist the action of penicillin's, broad-spectrum cephalosporin's and monobactam's [11]. Furthermore, there is an evidence indicating that most of ESBL producing bacteria are also resistant for carbapenem antibiotics $[12,13]$. ESBLs production is most commonly seen among Gram negative bacteria including Escherichia coli, Klebsiella pneumoniae, Proteus mirabilis and Pseudomonas aeruginosa [14].

Infections resulting from antibiotic resistant bacteria are more difficult and, in some instances, impossible to treat with current available antibiotics. Such infections lead to higher morbidity and mortality, imposing huge healthcare cost $[15,16]$. In recent years, varieties of bacteria are becoming resistant against two or more classes of antibiotics as a result of selective pressure or horizontal gene transfer. For instance, the magnitude of resistance seen among $E$. coli, S. aureus, Klebsiella species, P. aeruginosa, A. baumannii, and Enterobacter species is more threatening as these bacteria are the commonest etiologies for commonly observed hospital and community acquired infections [17, 18].

In Ethiopia, the patterns of antibiotic resistance among commonly seen bacterial etiologies have been described previously in different settings [19-21]. However, most of these studies did not address the magnitude of ESBL producing and carbapenem resistance patterns comprehensively. It is also known that bacterial antibiotic resistance is a dynamic process. Resistance patterns seen in the past might not be representing the current situation due to the strong correlation between efficiency of antibiotic use and antibiotic resistance. As a result, information about the current antibiotic resistance pattern of bacteria is very vital to understand the dynamic and trend of resistance.

Clinical characteristics of patients with HAIs at Jimma University Medical Center have recently been published. The incidence and overall prevalence of HAIs at the hospital were 28.15 per 1000 patient days and $19.41 \%$ respectively [22]. In the current study, we aimed to determine the MDR, XDR, PDR, ESBL mediated and carbapenem resistance patterns of bacteria isolated from patients with HAIs at the hospital.

\section{Methods and materials}

Institution based cross-sectional study was carried out in all wards of JUMC from May, 2016 to September, 2016. Totally, 1015 patients were admitted, of these 197 patients had sign of healthcare associated infection during the study time and all were taken as study participants. Microbiological investigation was done for 192 participants suspected to have healthcare associated infection; no microbiological test was done for the other five cases due to inability to obtain proper specimen. Different clinical specimens (blood, urine, wound swab, pus, and sputum) were collected aseptically from the patients with signs of healthcare associated infection. Bacterial identification was performed by standard microbiological methods which are adopted from CLSI guideline.

\section{Phenotypic determination of antibiotic susceptibility patterns}

Antibacterial susceptibility of Penicillin $(10 \mu \mathrm{g})$, Oxacillin $(1 \mu \mathrm{g})$, Gentamycin $(10 \mu \mathrm{g})$, Chloramphenicol $(30 \mu \mathrm{g})$, Tetracycline $(30 \mu \mathrm{g})$ Erythromycin $(15 \mu \mathrm{g})$, Trimethoprimsulfamethoxazole (1.25 g), Clindamycin $(2 \mu \mathrm{g})$, Cefoxitin $(30 \mu \mathrm{g})$, Ciprofloxacin $(5 \mu \mathrm{g})$, Nitrofurantoin $(300 \mu \mathrm{g})$, Norfloxacin $(10 \mu \mathrm{g})$, Ampicillin $(10 \mu \mathrm{g})$, Amoxicillin-clavulanic acid $(10 \mu \mathrm{g})$, Ceftriaxone $(30 \mu \mathrm{g})$, Ceftazidime $(30 \mu \mathrm{g})$, Cefepime $(30 \mu \mathrm{g})$, and Meropenem $(10 \mu \mathrm{g})$, (Oxoid, UK) were determined in vitro by Kirby-Bauer disk diffusion method following Clinical and Laboratory Standards Institute guidelines [23]. 


\section{ESBL and/or AmpC detection}

The presence of an ESBL and/or AmpC was determined with Cefpodoxime $(10 \mu \mathrm{g})$, Cefotaxime $(30 \mu \mathrm{g})$, Cefepime $(30 \mu \mathrm{g})$ and Ceftazidime $(30 \mu \mathrm{g})$ containing antibiotic discs (Mast Group, UK) by disc diffusion confirmation test. After the discs were inserted on inoculated plates, then they were incubated at $35-37^{\circ} \mathrm{C}$ for $18-24 \mathrm{~h}$ aerobically. Finally, zones of inhibition were read and recorded on excel sheet. The data from the excel sheet was transported to Mast group ESBL/AmpC and CARBA plus calculator spreadsheet (Mast group, UK) and reported as negative or positive for ESBL or/and AmpC and finally the results were recorded.

The results were registered as resistant, intermediate and susceptible; but for the sake of analysis intermediate and resistant isolates were grouped together as resistant. Classification of MDR, XDR and PDR were carried out according to Magiorakos et al, definitions [4]. All the antibiotic disks were from Oxoid (Oxoid, UK) and Mast discs (Mast group, UK). The inhibition zone diameter was measured using caliper and recorded on excel sheet.

\section{Data quality control}

Standard operating procedures (SOPs) were strictly followed while we did all bacteriological procedures starting from sample collection, isolation, identification and antibiotic susceptibility testing. Susceptible American Type Culture Collection (ATCC) 25,922 E. coli and ATCC 25923 Staphylococcus aureus were used as control strains and the test results were only accepted when the inhibition zone diameters of the above mentioned control strains were within performance ranges as described by CLSI [23]. ESBL positive ATCC 700603 Klebsiella pneumoniae and both ESBL and carbapenemase negative E. coli ATCC 25922 control strains were used in this study as positive and negative control respectively. To standardize the inoculum density of bacterial suspension for a susceptibility test, 0.5 McFarland standards, which is comparable with the approximate number of bacterial suspension $\left(1.0 \times 10^{8}\right.$ to $2.0 \times 10^{8}$ bacteria/ $\mathrm{mL})$, was used [23].

\section{Data analysis and statistical tests}

Data were double entered to Epi Data version 3.1 and transferred to SPSS version 20 and Microsoft Excel software for analysis and the results were presented as tables, pie-charts and graphs. $P$-values $<0.05$ were considered as statistically significant.

\section{Ethical consideration}

The study was approved by the Institutional Review Board of Institute of Health, Jimma University. Informed written consent was also obtained from participants and/or guardians after explaining the objective of the study. All the laboratory results were communicated as early as possible with the treating physicians for better management of the patients.

\section{Result \\ Socio-demography and background information of the participants}

From 1015 patients who were enrolled in the study; only 197 admitted patients had developed sign of healthcare associated infection with in the study time. Of these, 118 (59.9\%) patients had culture confirmed healthcare associated infections. Sociodemographic and clinical characteristics of study participants have recently been published. The incidence and overall prevalence of HAIs at the hospital were 28.15 per 1000 patient days and $19.41 \%$ respectively [22].

\section{Isolation rate}

Totally 240 clinical samples were obtained from 192 patients who were clinically diagnosed with healthcare associated infection. The most common sources of specimen were urine (55\%) followed by wound swab/pus (24.2\%), blood (15\%), and sputum (5.8\%). A total of 126 bacterial pathogens were isolated from 118 patient samples. A single organism was isolated from 110 (93.2\%) patient samples, and two organisms were isolated from 8 (6.8\%) patient samples who had been admitted to ICU. The overall culture positivity rate of participants was $118 / 192(61.5 \%)$. Most commonly isolated bacteria were E. coli 31(24.6\%), Klebsiella species $30(23.8 \%)$ and S. aureus 26 (20.6\%) (Fig. 1).

\section{Drug resistance patterns of isolates to different classes of antibiotics}

Antibiotic resistance patterns of the isolated pathogen of nosocomial origin are shown in Table 1. Half of $S$. aureus isolates were resistant to gentamicin $50.0 \%(13 / 26)$; and $53.84 \%(14 / 26)$ and $57.7 \%(15 / 26)$ of the isolates were resistant to methicillin /cefoxitin/oxacillin and ceftriaxone/chloramphenicol in vitro respectively; and all of $S$. aureus isolates were resistant against penicillin (Table 1). From a total of $26 \mathrm{~S}$. aureus isolates, 3(11.5\%), 10(38.5\%) 10 (38.5\%) and $3(11.6 \%)$ were MoDR, MDR, XDR and PDR respectively (Table 2).

From Gram negative bacteria, E. coli and Klebsiella species were the most frequent isolates. More than $90 \%$ of $E$. coli isolates were resistant against ampicillin, tetracycline and trimethoprim-sulfamethoxazole (Table 1). Conversely, only $16.1 \%$ of E.coli isolates were resistant against meropenem. Likewise, the resistance rate of Klebsiella species were $100 \%$ for ampicillin, $90 \%$ for tetracycline, $80 \%$ for trimethoprim 


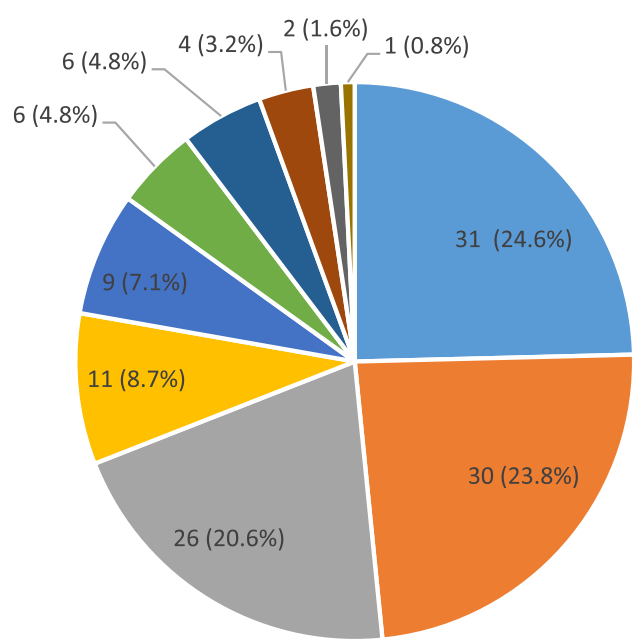

- E.coli

- Klebsiella species

- S. aureus

- Citrobacter species

- Pseudomans aeruginosa

- Enterobacter species

- Proteus species

- Providencia species

- A.buamannii

- Serratia species

Fig. 1 Proportions of isolated bacterial pathogens

-sulfamethoxazole, $40 \%$ for ciprofloxacin and 30\% for meropenem (Table 1).

\section{Classification of isolates based on their drug resistance pattern}

As shown in Table 2, among 126 bacterial isolates, 38 (30.2\%), 52 (41.3\%), and 24 (19\%) were MDR, XDR, and PDR respectively. Eight of the isolates were resistant to a single antimicrobial class and only four Klebsiella isolates were susceptible to all classes of the antimicrobials. The predominant isolates (E. coli, Klebsiella species and S. aureus) showed very high antimicrobial resistance patterns. The overall MDR rate of the isolated bacteria was $30.16 \%$. All bacteria isolated from ICU and pediatrics wards, $87.5 \%$ of bacteria isolated from Gynecology and obstetrics wards, $88 \%$ of bacteria isolated from Medical wards and $85.7 \%$ of bacteria isolated from surgical wards were MDR. The overall prevalence of PDR among all isolates was 19.0\%. Citrobacter species (45.4\%) and Pseudomonas aeruginosa (33.3\%) have shown high pandrug resistance rate. On the

Table 1 Frequency of antimicrobial resistant bacterial isolates for selected antimicrobial classes

\begin{tabular}{|c|c|c|c|c|c|c|c|c|c|c|c|}
\hline Antibiotic classes & Antibiotics & $\begin{array}{l}\text { S. aureus } \\
(n=26)\end{array}$ & $\begin{array}{l}\text { E. coli } \\
(n=31)\end{array}$ & $\begin{array}{l}\text { Klebsiella } \\
\text { species } \\
(n=30)\end{array}$ & $\begin{array}{l}\text { Citrobacter } \\
\text { species } \\
(n=11)\end{array}$ & $\begin{array}{l}\text { P. aeruginosa } \\
(n=9)\end{array}$ & $\begin{array}{l}\text { Enterobacter } \\
\text { species } \\
(n=6)\end{array}$ & $\begin{array}{l}\text { Proteus } \\
\text { species } \\
(n=6)\end{array}$ & $\begin{array}{l}\text { Providencia } \\
\text { species } \\
(n=4)\end{array}$ & $\begin{array}{l}\text { A. buamannii } \\
(n=2)\end{array}$ & $\begin{array}{l}\text { Serratia } \\
\text { species } \\
(n=1)\end{array}$ \\
\hline \multirow{5}{*}{$\begin{array}{l}\text { Penecillins } \\
\text { 3rd and 4th } \\
\text { generation } \\
\text { cephalosporins }\end{array}$} & Penicillin & 26 & - & - & - & - & - & - & - & - & - \\
\hline & Ampicillin & - & 29 & 30 & 11 & 9 & 6 & 5 & 4 & 2 & 1 \\
\hline & Ceftriaxone & 15 & 15 & 16 & 7 & 9 & 4 & 4 & 2 & 2 & 1 \\
\hline & Ceftazidime & - & 16 & 17 & 8 & 8 & 5 & 4 & 2 & 2 & 1 \\
\hline & Cefepime & - & 14 & 15 & 6 & 5 & 2 & 4 & 2 & 2 & 1 \\
\hline $\begin{array}{l}\text { Anti-staphylococcal } \\
\beta \text {-lactams }\end{array}$ & Oxacillin & 14 & - & - & - & - & - & - & - & - & - \\
\hline Cephamycins & Cefoxitin & 14 & 19 & 23 & 6 & 8 & 6 & 4 & 1 & 2 & 1 \\
\hline Aminoglycosides & Gentamycin & 13 & 22 & 21 & 7 & 8 & 3 & 3 & 1 & 2 & 1 \\
\hline Phenicols & Chloramphenicol & 15 & 19 & 20 & 8 & 9 & 1 & 3 & 3 & 2 & 1 \\
\hline Macrolides & Erythromycin & 19 & - & - & - & - & - & - & - & - & - \\
\hline Lincosamides & Clindamycin & 17 & - & - & - & - & - & - & - & - & - \\
\hline Tetracycline & Tetracycline & 17 & 29 & 27 & 7 & 9 & 4 & 6 & 4 & 2 & 1 \\
\hline $\begin{array}{l}\text { Folate pathway } \\
\text { inhibitors }\end{array}$ & $\begin{array}{l}\text { Trimethoprim- } \\
\text { sulfamethoxazole }\end{array}$ & 19 & 28 & 24 & 9 & 4 & 2 & 6 & 3 & 2 & 1 \\
\hline Fluoroquinolones & Ciprofloxacin & 16 & 14 & 12 & 6 & 6 & 3 & 3 & 2 & 1 & 1 \\
\hline Carbapenems & Meropenem & - & 5 & 9 & 2 & 4 & 1 & 0 & 1 & 2 & 1 \\
\hline $\begin{array}{l}\text { Penecillins + } \\
\beta \text {-lactamase } \\
\text { inhibitors }\end{array}$ & $\begin{array}{l}\text { Amoxicillin- } \\
\text { clavulanic acid }\end{array}$ & - & 28 & 29 & 9 & 9 & 6 & 6 & 4 & 2 & 1 \\
\hline
\end{tabular}


Table 2 Frequency distribution of MultiS, MoDR, MDR, XDR, and PDR pattern of isolated bacteria

\begin{tabular}{lllllll}
\hline Isolated organisms & Total & Multis & MoDR & MDR & XDR & PDR \\
\hline S. aureus & 26 & 0 & 3 & 10 & 10 & 3 \\
E. coli & 31 & 0 & 3 & 11 & 10 & 7 \\
Klebsiella species & 30 & 4 & 2 & 9 & 13 & 2 \\
Citrobacter species & 11 & 0 & 0 & 2 & 4 & 5 \\
Enterobacter species & 6 & 0 & 0 & 2 & 3 & 1 \\
Proteus species & 6 & 0 & 0 & 2 & 4 & 0 \\
Providencia species & 4 & 0 & 0 & 0 & 3 & 1 \\
Pseudomonas aeruginosa & 9 & 0 & 0 & 2 & 4 & 3 \\
Acinetobacter baumannii & 2 & 0 & 0 & 0 & 1 & 1 \\
Serratia species & 1 & 0 & 0 & 0 & 0 & 1 \\
Total & 126 & 4 & 8 & 38 & 52 & 24
\end{tabular}

MultiS, susceptible to all antibiotic classes; MoDR, resistant to single antibiotic class; MDR, resistant to at least one agent in three or more antimicrobial categories; XDR, resistant to at least one agent in all but two or fewer antimicrobial categories (i.e. bacterial isolates remain susceptible to only one or two categories); PDR, resistant to all antibiotic classes. Source: Based on definitions by Magiorakos et al. [4]

other hand, Klebsiella species (6.6\%) and S.aureus (11.5\%) have shown the least PDR rate. E.coli (22.6\%) and Enterobacter species (16.7\%) have also shown a moderate PDR rate.

\section{Prevalence of ESBL, AmpC, and Carbapenemase producing isolates}

Of the 1 hundred isolated gram-negative rods, 36 and $7 \%$ were positive for extended spectrum beta-lactamase (ESBL) and AmpC respectively. Eight percent of the isolates were positive for both extended spectrum betalactamase (ESBL) and AmpC. With regard to the proportion of carbapenemase producing isolates, $25 \%$ of gram negative isolates have shown carbapenem resistance (Table 3). To be precise, $16.1 \%$ of E.coli and $30.0 \%$ of Klebsiella species were carbapenem resistant isolates (Table 3).

\section{Antimicrobial resistance pattern and impact on clinical outcome}

Of 118 patients with culture confirmed healthcare associated infection, 13 patients (11.02\%) died and all of the isolated microorganisms from these 13 patients were multidrug resistant (MDR) as shown in Table 4. The mean hospital stays of the patients infected with MDR bacteria were $15.4 \pm 9.6$ days (range $3-49$ days). There is statistically significant association between mean duration of stay and infection with MDR bacteria (Table 4).

\section{Discussion}

The overall rate of MDR, XDR and PDR bacterial isolates from JUMC were found to be 30.16, 41.27 and $19.0 \%$ respectively. Furthermore, the observed MDR rate is significantly associated with prolonged hospital stay and all patients, who died, were infected with MDR bacterial species (even if, it is not statistically significant). On the other hand, the observed XDR and PDR rate at the hospital indicates that the problem of AMR is increasing at an alarming rate and pathogenic bacteria that circulate in JUMC are becoming more resistant to all available antibiotics. The occurrence of PDR pathogenic bacteria would also have huge potential threat and implications for patient care in the hospital and the community at large. As we are living in the era of very connected world, it is highly likely for these PDR bacteria to be disseminated to other parts of Ethiopia and other parts of the world as well.

To the best of our knowledge, there is no previous report from Ethiopia on the rate of XDR and PDR pathogenic bacteria to compare with this result. It is possible to list some reasons which might have contributed for this observed high XDR and PDR rate. The first reason might be associated with lack of AMR surveillance and stewardship program at JUMC and in Ethiopia in general. There is enough evidence that indicates AMR surveillance and stewardship program helps to understand

Table 3 Prevalence of ESBL, AmpC, and Carbapenem resistant isolates of gram negative rods

\begin{tabular}{|c|c|c|c|c|c|c|c|}
\hline \multirow[t]{2}{*}{ Isolated organisms } & \multirow[t]{2}{*}{ Total } & \multicolumn{4}{|c|}{ ESBL \& AmpC producing isolates } & \multicolumn{2}{|c|}{ Carbapenemase resistance } \\
\hline & & Not ESBL \& AmpC, N (\%) & ESBL, N (\%) & AmpC, N (\%) & ESBL \& AmpC, N (\%) & Yes, N (\%) & No, N (\%) \\
\hline E. coli & 31 & $12(38.7)$ & $14(45.2)$ & $3(9.7)$ & $2(6.5)$ & $5(16.1)$ & $26(83.9)$ \\
\hline Klebsiella species & 30 & $14(46.7)$ & $13(43.3)$ & $2(6.7)$ & $1(3.3)$ & $9(30.0)$ & $21(70.0)$ \\
\hline Citrobacter species & 11 & 5 & 4 & 0 & 2 & 2 & 9 \\
\hline Enterobacter species & 6 & 2 & 3 & 0 & 1 & 1 & 5 \\
\hline Proteus species & 6 & 5 & 1 & 0 & 0 & 0 & 6 \\
\hline Providencia species & 4 & 1 & 2 & 1 & 0 & 1 & 3 \\
\hline Pseudomonas aeruginosa & 9 & 5 & 1 & 1 & 2 & 4 & 5 \\
\hline Acinetobacter baumannii & 2 & 2 & 0 & 0 & 0 & 2 & 0 \\
\hline Serratia species & 1 & 1 & 0 & 0 & 0 & 1 & 0 \\
\hline Total & 100 & 49 & 36 & 7 & 8 & 25 & 75 \\
\hline
\end{tabular}


Table 4 Antimicrobial resistance and associated factors

\begin{tabular}{|c|c|c|c|}
\hline Variable & Non MDR $(N=12)(\%)$ & $\operatorname{MDR}(N=106)(\%)$ & $P$ \\
\hline \multicolumn{4}{|c|}{ History of treatment ${ }^{a}$} \\
\hline No & $9(75.0)$ & 85 (80.19) & \\
\hline Yes & $3(25.0)$ & $21(19.81)$ & 0.672 \\
\hline \multicolumn{4}{|c|}{ Patient outcome } \\
\hline Progress & $12(100)$ & $93(87.74)$ & \\
\hline Died & 0 & $13(12.26)$ & 0.198 \\
\hline \multicolumn{4}{|c|}{ Duration of stay in Hospital } \\
\hline$<=15$ days & $8(66.6)$ & $25(23.58)$ & \\
\hline$>15$ days & $4(33.4)$ & $81(76.42)$ & 0.002 \\
\hline
\end{tabular}

Non-MDR: susceptible to all antibiotic classes/resistant to one/two antibiotic classes; MDR: resistant to at least one agent in three or more antimicrobial categories Magiorakos et al. [4]

a taking antibiotics in the last 3 months of the study period

the pattern of resistance and improve the utilization of antibiotics to prevent occurrence of antibiotic resistance.

The second reason might be associated with lack of comprehensive national antibiotic policies and problems in implementations of policies. In Ethiopia, there is no clear antibiotic policy and controlling mechanism about antibiotic usage. It is a common practice in Ethiopia to buy any antibiotic from private drug vendors and pharmacies without any prescription. This might have contributed for emergence and dissemination of antibiotic resistant bacteria at different settings. The third reason might be associated with lack of system to assess the quality and reliability of imported antibiotics in Ethiopia. For instance, one previous study which assessed the quality of anti-tuberculosis drugs in Ethiopia in 2013 has indicated that around $17 \%$ of anti TB drugs were fake drugs [24]. It is easy to imagine the role of these fake drugs on anti TB drug resistance. Likewise, though there is no previous research done in Ethiopia to assess the quality of antibiotics dispensed in private and government pharmacies, it is highly likely that some of them might be sub-standard, given that substantial proportion of the antibiotics in private pharmacies are supplied through unknown routes $[25,26]$.

The emergence of ESBL producing gram negative rods have become a rising concern in the developing world [27]. In this study, phenotypically, the most common ESBL producing microorganisms were $E$. coli and Klebsiella species which are 51.6\% (16/31) and $46.7 \%(14 / 30)$ respectively; which is comparable with the studies done in Nigeria, Nepal and Burma in which ESBL producing Enterobacteriaceae were $44.3,43.7$ and $38.0 \%$ respectively [14, 28, 29]. However, the other studies done in India and Nepal showed that 30.18 and $18.4 \%$ of Klebsiella pneumoniae produce ESBL respectively which is lower than our report [30,31]. Even though the prevalence of ESBLs is not well documented, in many parts of the world $10-40 \%$ of strains of Escherichia coli and Klebsiella pneumoniae are estimated to produce ESBLs [27]. High proportion of ESBL producing isolates was documented in the current study which might be due to the fact that our study participants were all hospitalized; since hospitalization was identified as the strongest independent risk factor to express ESBL [32].

Regarding to carbapenem resistance, 19 (21.4\%), 4 (44.4\%) and 2 (100\%) of the Enterobacteriaceae, P. aeruginosa and $A$. buamannii were carbapenem resistant respectively which are found in the priority one list according to WHO classification [33]. In addition to that, $53.8 \%$ of the other commonly isolated S. aureus were methicillin resistant which also needs high attention. Therefore, high attention should be given to these pathogens which are considered as priority one and two according to WHO [33]. To compare with other similar studies, the rate of carbapenem resistance among E.coli (16.1\%) and Klebsiella species (30\%) is consistent with multinational study done in Europe [34]. In contrary, 25\% carbapenem resistance rate observed in this study is lower than a report from Brazil which was 100\% [35]. This could be explained by the difference in utilization of carbapenem antibiotics to treat different infections in the respective setups [36, 37]. The observed high carbapenem resistance rate can also be due to prescription of antibiotics without the knowledge of their susceptibility pattern, or introduction and dissemination of carbapenem resistant bacteria strains from other areas with high resistance rate might also be possible as JUMC is frequently visited by different European, Chinese and Korean nationalities due to different collaborative researches, training and service activities.

As reported by other studies, meropenem was the most effective antibiotic against most gram-negative rods [38]. To control high rate of antibiotic resistant isolates coordinated and urgent action is needed to prevent the development of drug resistance in the setting. Surveillance on antibiotic resistance will also be most useful to decide the correct empirical treatment and will help to control and prevent infections caused by resistant pathogens. Furthermore, our data suggest that the most effective antibiotics for gram-negative bacilli in vitro are meropenem followed by cefepime and for gram-positive organisms less resistance was observed against gentamycin.

\section{Conclusion}

In this study, high antimicrobial resistance rate was demonstrated. The observed high PDR, ESBL and carbapenem resistance rate is worrisome. Coordinated effort 
is needed from all stakeholders working in health system in Ethiopia to tackle this important public health problem. An immediate action should be taken at the hospital to start antibiotic stewardship program to reduce the observed antibiotic resistance and prevent further complications.

\section{Abbreviations}

HAl: Health care associated infection; MDR: Resistant to at least one agent in three or more antimicrobial categories; MoDR: Resistant to single antibiotic class; Multis: Susceptible to all antibiotic classes; PDR: Resistant to all antibiotic classes; XDR: Resistant to at least one agent in all but two or fewer antimicrobial categories (i.e. bacterial isolates remain susceptible to only one or two categories)

\section{Acknowledgements}

We would like to thank Jimma University for funding this research and we would also like to thank all laboratory personnels working at Jimma University Medical Center, bacteriology laboratory for their unreserved support during data collection.

\section{Funding}

This project was funded by Jimma University through the Institute of Health, Research and Postgraduate Office.

\section{Availability of data and materials}

NA

\section{Authors' contributions}

MG, SA, EKG \& MB conceived, designed, instrument development, supervision of data collection, analysis and manuscript writing. SB, GK, LT, YY, YA, NF, HA, and AW, participated in study design, development of instruments, supervision of data collection and editing and revision of the manuscript. All authors read and approved the final manuscript.

\section{Ethics approval and consent to participate}

The study was approved by the Institutional Review Board of Institute of Health, Jimma University with the committee's reference number RPGe/ $355 / 2016$.

\section{Consent for publication}

Not applicable - This manuscript does not contain any individual person's data.

\section{Competing interests}

The authors declare that they have no competing interests.

\section{Publisher's Note}

Springer Nature remains neutral with regard to jurisdictional claims in published maps and institutional affiliations.

\section{Author details}

${ }^{1}$ School of Medical Laboratory Science, Jimma University, Jimma, Ethiopia. ${ }^{2}$ Department of Pediatrics and Child Health, Jimma University, Jimma, Ethiopia. ${ }^{3}$ Department of Ophthalmology, Jimma University, Jimma, Ethiopia. ${ }^{4}$ Department of Surgery, Jimma University, Jimma, Ethiopia. ${ }^{5}$ Department of Obstetrics and Gynecology, Jimma University, Jimma, Ethiopia. ${ }^{6}$ Department of Health Education and Behavioral Health, Jimma University, Jimma, Ethiopia. ${ }^{7}$ Department of Epidemiology and Statistics, Jimma University, Jimma, Ethiopia. ${ }^{8} \mathrm{Head}$ of the parasitology laboratory and deputy head of the molecular diagnostics laboratory at the Max von Pettenkofer-Institute, Ludwigs-Maximilians-University (LMU), München, Germany. ${ }^{9}$ Department of Internal Medicine, Jimma University, Jimma, Ethiopia. ${ }^{10}$ WHO-TDR clinical research former fellow at AERAS Africa and Rockville, Rockville, MD, USA.

${ }^{11}$ Institute of Health, Jimma University, P.O. Box 1368, Jimma, Ethiopia.
Received: 14 May 2018 Accepted: 8 November 2018

Published online: 19 November 2018

\section{References}

1. Chakraborty A, Pal NK, Sarkar S, Gupta MS. Antibiotic resistance pattern of Enterococci isolates from nosocomial infections in a tertiary care hospital in Eastern India. J Natl Sci Biol Med. 2015:6(2):394.

2. Colodner R, Rock W, Chazan B, Keller N, Guy N, Sakran W, et al. Risk factors for the development of extended-spectrum beta-lactamase-producing bacteria in nonhospitalized patients. Eur J Clin Microbiol Infect Dis. 2004; 23(3):163-7.

3. Ayukekbong JA, Ntemgwa M, Atabe AN. The threat of antimicrobial resistance in developing countries: causes and control strategies. Antimicrob Resist Infect Control. 2017;6(1):47.

4. Magiorakos AP, Srinivasan A, Carey R, Carmeli Y, Falagas M, Giske C, et al. Multidrug-resistant, extensively drug-resistant and pandrug-resistant bacteria: an international expert proposal for interim standard definitions for acquired resistance. Clin Microbiol Infect. 2012;18(3):268-81.

5. Lashinsky JN, Henig O, Pogue JM, Kaye KS. Minocycline for the Treatment of Multidrug and Extensively Drug-Resistant A. baumannii: A Review. Infect Dis Ther. 2017;6:1-13.

6. Bouchillon S, Johnson B, Hoban D, Johnson J, Dowzicky M, Wu D, et al. Determining incidence of extended spectrum $\beta$-lactamase producing Enterobacteriaceae, vancomycin-resistant enterococcus faecium and methicillin-resistant Staphylococcus aureus in 38 centres from 17 countries: the PEARLS study 2001-2002. Int J Antimicrob Agents. 2004;24(2):119-24.

7. Organization WH. Antimicrobial resistance: global report on surveillance: World Health Organization; 2014.

8. Pitout JD, Laupland KB. Extended-spectrum $\beta$-lactamase-producing Enterobacteriaceae: an emerging public-health concern. Lancet Infect Dis. 2008;8(3):159-66.

9. Fridkin S, Baggs J, Fagan R, Magill S, Pollack LA, Malpiedi P, et al. Vital signs: improving antibiotic use among hospitalized patients. MMWR Morb Mortal Wkly Rep. 2014;63(9):194-200.

10. Fernando M, Luke W, Miththinda J, Wickramasinghe R, Sebastiampillai B, Gunathilake $M$, et al. Extended spectrum beta lactamase producing organisms causing urinary tract infections in Sri Lanka and their antibiotic susceptibility pattern-a hospital based cross sectional study. BMC Infect Dis. 2017;17(1):138

11. Tang SS, Apisarnthanarak A, Hsu LY. Mechanisms of $\beta$-lactam antimicrobial resistance and epidemiology of major community-and healthcare-associated multidrug-resistant bacteria. Adv Drug Deliv Rev. 2014;78:3-13.

12. Miriagou V, Cornaglia G, Edelstein M, Galani I, Giske C, Gniadkowski M, et al. Acquired carbapenemases in gram-negative bacterial pathogens: detection and surveillance issues. Clin Microbiol Infect. 2010;16(2):112-22.

13. Kumarasamy KK, Toleman MA, Walsh TR, Bagaria J, Butt F, Balakrishnan R, et al. Emergence of a new antibiotic resistance mechanism in India, Pakistan, and the UK: a molecular, biological, and epidemiological study. Lancet Infect Dis. 2010:10(9):597-602.

14. Ogefere HO, Aigbiremwen PA, Omoregie R. Extended-Spectrum Betalactamase (ESBL)-producing gram-negative isolates from urine and wound specimens in a tertiary health Facility in Southern Nigeria. Trop J Pharm Res. 2015:14(6):1089-94.

15. Kollef KE, Schramm GE, Wills AR, Reichley RM, Micek ST, Kollef MH. Predictors of 30-day mortality and hospital costs in patients with ventilatorassociated pneumonia attributed to potentially antibiotic-resistant gramnegative bacteria. CHEST Journal. 2008;134(2):281-7.

16. Mauldin PD, Salgado CD, Hansen IS, Durup DT, Bosso JA. Attributable hospital cost and length of stay associated with health care-associated infections caused by antibiotic-resistant gram-negative bacteria. Antimicrob Agents Chemother. 2010;54(1):109-15.

17. Silvestri L, van Saene $H$. Hospital-acquired infections due to gram-negative bacteria. N Engl J Med. 2010;363(15):1482-6

18. Finley RL, Collignon P, Larsson DJ, McEwen SA, Li X-Z, Gaze WH, et al. The scourge of antibiotic resistance: the important role of the environment. Clin Infect Dis. 2013:57(5):704-10.

19. Abera B, Kibret M, Mulu W. Extended-Spectrum beta ( $\beta$ )-lactamases and Antibiogram in Enterobacteriaceae from clinical and drinking water Sources from Bahir Dar City, Ethiopia. PloS one. 2016;11(11):e0166519. 
20. Desta K, Woldeamanuel Y, Azazh A, Mohammod H, Desalegn D, Shimelis D, et al. High Gastrointestinal Colonization Rate with Extended-Spectrum $\beta$ Lactamase-Producing Enterobacteriaceae in Hospitalized Patients: Emergence of Carbapenemase-Producing K. pneumoniae in Ethiopia. PloS one. 2016;11(8):e0161685.

21. Mulualem Y, Kasa T, Mekonnen Z, Suleman S. Occurrence of extended spectrum beta (b)-lactamases in multidrug resistant Escherichia coli isolated from a clinical setting in Jimma university specialized hospital, Jimma, Southwest Ethiopia. East Afr J Public Health. 2012;9(2):58-61.

22. Ali S, Birhane M, Bekele S, Kibru G, Teshager L, Yilma Y, et al. Healthcare associated infection and its risk factors among patients admitted to a tertiary hospital in Ethiopia: Iongitudinal study. Antimicrob Resist Infect Control. 2018;7(1):2.

23. Wayne P. Clinical and laboratory standards institute. Perform Stand Antimicrob Susceptibility Testing. 2007;17.

24. Bate R, Jensen P, Hess K, Mooney L, Milligan J. Substandard and falsified anti-tuberculosis drugs: a preliminary field analysis. Int J Tuberc Lung Dis. 2013;17(3):308-11.

25. WHO. 1 in 10 medical products in developing countries is substandard or falsified. Geneva: World Health Organization; 2017.

26. WHO. Global Surveillance and Monitoring System for substandard and falsifed medical products. Geneva: World Health Organization; 2017. Licence: CC BY-NC-SA 3.0 IGO

27. Rupp ME, Fey PD. Extended spectrum $\beta$-lactamase (ESBL)-producing Enterobacteriaceae. Drugs. 2003;63(4):353-65.

28. Parajuli NP, Acharya SP, Mishra SK, Parajuli K, Rijal BP, Pokhrel BM. High burden of antimicrobial resistance among gram negative bacteria causing healthcare associated infections in a critical care unit of Nepal. Antimicrob Resist Infect Control. 2017;6(1):67.

29. Myat TO, Hannaway RF, Zin KN, Htike WW, Win KK, Crump JA, et al. ESBL-and carbapenemase-producing enterobacteriaceae in patients with bacteremia, Yangon, Myanmar, 2014. Emerg Infect Dis. 2017;23(5):857.

30. Shukla I, Tiwari R, Agrawal M. Prevalence of extended spectrum-lactamase producing Klebsiella pneumoniae in a tertiary care hospital. Indian J Med Microbiol. 2004;22(2):87.

31. Chaudhary P, Bhandari D, Thapa K, Thapa P, Shrestha D, Chaudhary H, et al. Prevalence of extended Spectrum Beta-lactamase producing Klebsiella Pneumoniae isolated from urinary tract infected patients. J Nepal Health Res Counc. 2016;14(33):111-5.

32. Bisson G, Fishman NO, Patel JB, Edelstein PH, Lautenbach E. Extendedspectrum $\beta$-lactamase-producing Escherichia coli and Klebsiella species: risk factors for colonization and impact of antimicrobial formulary interventions on colonization prevalence. Infect Control Hospital Epidemiol. 2002;23(5):254-60.

33. Organization WH. Global priority list of antibiotic-resistant bacteria to guide research, discovery, and development of new antibiotics. Geneva: World Health Organization; 2017.

34. Grundmann H, Glasner C, Albiger B, Aanensen DM, Tomlinson CT, Andrasević AT, et al. Occurrence of carbapenemase-producing Klebsiella pneumoniae and Escherichia coli in the European survey of carbapenemase-producing Enterobacteriaceae (EUSCAPE): a prospective, multinational study. Lancet Infect Dis. 2017;17(2):153-63.

35. Gonçalves IR, Ferreira M, Araujo B, Campos P, Royer S, Batistão D, et al. Outbreaks of colistin-resistant and colistin-susceptible KPC-producing Klebsiella pneumoniae in a Brazilian intensive care unit. J Hosp Infect. 2016;94(4):322-9.

36. Kebede HK, Gesesew HA, Woldehaimanot TE, Goro KK. Antimicrobial use in paediatric patients in a teaching hospital in Ethiopia. PLoS One. 2017;12(3):e0173290

37. Yadesa TM, Gudina EK, Angamo MT. Antimicrobial use-related problems and predictors among hospitalized medical in-patients in Southwest Ethiopia: prospective observational study. PLoS One. 2015;10(12):e0138385.

38. Alexopoulou A, Vasilieva L, Agiasotelli D, Siranidi K, Pouriki S, Tsiriga A, et al. Extensively drug-resistant bacteria are an independent predictive factor of mortality in 130 patients with spontaneous bacterial peritonitis or spontaneous bacteremia. World J Gastroenterol. 2016;22(15):4049.

\section{Ready to submit your research? Choose BMC and benefit from:}

- fast, convenient online submission

- thorough peer review by experienced researchers in your field

- rapid publication on acceptance

- support for research data, including large and complex data types

- gold Open Access which fosters wider collaboration and increased citations

- maximum visibility for your research: over $100 \mathrm{M}$ website views per year

At BMC, research is always in progress.

Learn more biomedcentral.com/submissions 